\title{
Examining the effectiveness of the simplified air-cargo express consignment clearance system in Taiwan
}

Tao Chen(1)

\author{
Correspondence: \\ chentao@mail.knu.edu.tw; \\ chentaoknu@gmail.com \\ Department of Logistics and \\ Shipping Management, Kainan \\ University, Taoyuan, Taiwan
}

\begin{abstract}
The Simplified Express Consignment Clearance System was first introduced in Taiwan in 2001 to improve the effectiveness and efficiency of customs clearance operations of air cargo. This system, which is based on simplified declaration procedures, is expected to facilitate the effective and efficient collection of taxes and duties even with limited manpower. The Customs Administration (CA) has highlighted the system's efficiency, but its effectiveness is yet to be validated. Thus, this study comprehensively examines this system by adopting both bottom-up and top-down approaches from operation and policy perspectives.

Import express cargo clearance records were collected and logistic regression analysis was performed to identify critical factors that influence the system's effectiveness. Results reveal the "inspector" to be the most significant factor. Having a diligent inspector will result in a high number of customs declarations that should be charged for duties or taxes with penalty. This finding questions the notion that the inspector is indeed the most significant factor. Thus, the scope of this study was expanded to cover the simplified system's policy and structure, and concerned parties were interviewed to gain an in-depth understanding. Findings reveal that the system flaw originates from the inability of the simplified system to perform its designated function. This paper offers several contributions to the literature. First, this paper examines the CA's development of the simplified clearance system. Second, this paper provides a detailed analysis of the consignment clearance system's effectiveness and its critical influencing factors. Third, the paper provides new insights into the system flaw and examines the trade-off between the system's efficiency and effectiveness.
\end{abstract}

Keywords: Simplified express consignment clearance system, Customs administration, Tax evasion, System flaw, Taiwan

\section{Introduction}

The Simplified Express Consignment Clearance System (the SECCS) for aircargo was introduced in Taoyuan Airport, Taiwan, in 2001 to provide an efficient consignment clearance service for express aircargo operators. This system has booted efficiency by streamlining the declaration procedures. However, the Customs Administration (CA), customs officers, customs brokers, and consignees disagree as regards the effectiveness of the SECCS. To conduct a comprehensive analysis of the system, this study examines the SECCS operations in detail and identifies the critical influencing factors. Suggestions

(c) The Author(s). 2016 Open Access This article is distributed under the terms of the Creative Commons Attribution 4.0 International License (http://creativecommons.org/licenses/by/4.0/), which permits unrestricted use, distribution, and reproduction in any medium, provided you give appropriate credit to the original author(s) and the source, provide a link to the Creative Commons license, and indicate if changes were made. 
based on the findings are then offered to strengthen the system's effectiveness. The research scope is expanded to cover the development and structure of the SECCS. This paper makes several contributions. First, this paper examines the CA's development of the express consignment clearance system. Second, this paper analyzes the consignment clearance system's effectiveness and identifies critical factors. Third, this paper provides new insights into the system flaw and examines the trade-off between the system's efficiency and effectiveness.

\section{Literature review and express operations}

\section{Customs administration and express air-cargo operations}

Maintaining the balance between effectiveness and efficiency for cargo inspection, particularly for express cargoes that demand high efficiency, is a challenge for the CA (WCO, 1999). From the standpoint of the CA, their major tasks include collecting taxes and duties as well as preventing the import of cargoes threatening national security; efficiency has never been a major concern for the CA. However, from the perspective of national interest, improving the competitiveness of Taiwan's international logistics industry would be greatly beneficial to the country. For example, building a friendly trade and logistics environment with efficient customs operations would entice international express operators to use Taiwan as a regional hub. For this reason, regulations and rules that could accelerate express cargo operations have been introduced in the 2000s.

Many studies have explored the CA and its impact on the logistics industry. For example, Heaver (1992) examined the efficiency and effectiveness of the CA in several countries, the manner by which the CA could implement "seamless" international logistics, and the extent to which efficiency affects the competitiveness of countries and consequently attract international logistics businesses. Numerous studies have focused on methods for improving the effectiveness and efficiency of the CA. Geourjon and Laporte (2005) investigated the revenue performance of the CA and concluded that the use of a sophisticated risk management method can facilitate trade and enhance performance. Cantens et al. (2010) adopted performance measures to improve the effectiveness and efficiency of the CA. Duval et al. (2006) reviewed the express consignment clearance procedures in Asia from an operational perspective and compared their differences in detailed operation procedures. Puengpradit (2010) examined the operations in Thailand and identified discrepancies between policy and implementation, particularly in risk management, customs procedures, and information technology; this study also recommended methods for maintaining the balance between trade facilitation and regulatory control.

Studies on express consignment systems or simplified consignment systems have primarily emphasized their benefits and importance to international logistics businesses. For example, Zhang (2002) analyzed the simplified consignment system from both policy and technological perspectives, as well as the system's importance in facilitating air-cargo operational efficiency. Album (2010) studied the advantages of a simplified express consignment system from the standpoint of regional cooperation of trade facilitation. Salama and Şenbursa (2014) demonstrated how quantified cost efficiency can be realized by implementing electronic data interchange (EDI) and electronic communications in consignment systems from the viewpoint of shipping forwarders. 
Only a few papers have analyzed system flaw or failure. Chapman (2004) discussed the possibility of system flaw or failure in public policy, its possible effect, and the causes of system failure. Yeh (2008) examined the immigration legal system and its flaw, and offered possible reforms to achieve an improved performance.

Lastly, only a few papers have examined the consignment clearance system in detail presumably because of the difficulty associated with collecting examples and cases concerning customs operations. The present paper explores the policy of the CA regarding the SECCS and the simplified clearance system's effectiveness, and the findings will be the major contributions of this work.

\section{Development of the air express consignment clearance system in Taiwan}

In the 1980s, the air express business was originally operated by airlines that used "on board courier" (OBC) with their excess cargo capacity to transport express cargoes. $\mathrm{OBC}$ uses the passenger channel, and the cargo passes through customs inspection under the name of luggage, with simple clearance procedures and most of the time, with no tax and duties being charged. Not surprisingly, the widespread dispute over the concern of tax evasion for $\mathrm{OBC}$ prompted the $\mathrm{CA}$ to regulate the weight and value of the cargo to be transported via OBC. For example, the maximum gross weight of a bag should be $40 \mathrm{~kg}$, and the cost, insurance, and freight (CIF) value of each bag should be lower than NT\$20,000 (US\$500). Either the CIF value or the weight of the bag that is higher than the regulated one, along with its document, should be inspected as cargo and be charged with imposed taxes and duties accordingly.

In the 1990s, Taiwan began to compete with its neighboring countries for the position of "regional operation center" or "regional hub." Hence, Taiwan endeavored to entice international express operators to choose Taoyuan Airport as their regional hub. In the meantime, the Taiwan government directed the CA to provide efficient international logistics service to meet the demand of international express operators. In 1995, the CA announced the Notice for Express Cargo Consignment Clearance to regulate express business in the airport; meanwhile, the express handling zone has been established, which is dedicated for the storage and inspection of express cargo. In 1996, to attract international express operators, such as FedEx Corporation (FedEx) and United Parcel Service (UPS), the CA further increased the maximum gross weight of a bag from $40 \mathrm{~kg}$ to $70 \mathrm{~kg}$, and raised the CIF value of each bag from NT\$20,000 (US\$500) to NT\$50,000 (US\$1250) as incentives, as shown in Table 1.

In 2001, the CA launched the SECCS. Customs brokers can use EDI to transmit data to Trade-Van, which will subsequently transmit the data to the CA. This system achieves paperless customs operations and reduces the time required for customs clearance. When the simplified system was first introduced in 2001, around $80 \%$ of express cargoes use the

Table 1 Changes of the definitions of the 'bag' in express operation

\begin{tabular}{lll}
\hline Year \} $&{\text { Maximum weight of bag }} &{\text { Maximum CIF value }} \\
{\hline 1980} &{40 \mathrm{~kg}} &{\text { US\$500 }} \\
{1996} &{70 \mathrm{~kg}} &{\text { US\$1250 }} \\
{\hline}$
\end{tabular}

Source: Customs Administration, Ministry of Finance, Taiwan 
simplified system. However, in 2015, around $92 \%$ of import express cargoes used the SECCS because of its simplified procedures and efficiency (see Table 2).

Express operations are handled by four air-cargo terminals at Taoyuan Airport. Among these terminals, the Taiwan Air Cargo Terminal (TACT) and Evergreen Air Cargo Service Corporation (EGAC) were established by China Air and Eva Air, respectively. Two international express operators, namely, FedEx and UPS, rented space with dedicated areas and exclusive express cargo processing systems from TACT and EGAC. Meanwhile, DHL has been renting a warehouse from Far Glory Terminal since 2009, but the cargo volume handled by DHL has been counted as part of the traffic of Far Glory. The traffic of express cargo handled by operators at Taoyuan Airport in 2014 is shown in Table 3.

\section{Customs inspections for express cargo}

In the express clearance consignment operations, the cargoes will be inspected by three channels based on the nature of the cargo declared by the broker/consignee, and the definitions of the channels are shown in Table 4.

The Regulations for Express Cargo Clearance have categorized the express cargoes into four types for customs clearance based on the imposed tax to be charged, as shown in Table 5.

The collection of customs duties and prevention of smuggling are the two major tasks of the CA. Both the number of tax evasion cases captured and the value of smuggled cargoes captured have been used as key performance indicators to measure the effectiveness of the SECCS.

The SECCS utilizes the "expert system" to control risks and select the cargoes for inspection. The expert system uses 17 criteria to monitor high-risk brokers and consignees (see Table 6). In practice, the expert system selects approximately 2 to $3 \%$ of the cargoes for inspection.

\section{Research findings and analysis}

\section{Data collection and general analysis}

Given the limitation of networking and access of information, this study collected the operational data of X Terminal between January 2011 and March 2011. Considering the confidentiality of the information concerning the SECCS, the research results cannot be published before February 2015. As a result of data collection, a total of 251 official tax evasion records together with their detailed information were successfully collected. This information will be used to identify the critical factors that influence the SECCS' effectiveness.

Table 2 Number of import air express cargoes cleared in recent years (Measured by declarations)

\begin{tabular}{llll}
\hline Years \Channel & Simplified Express Consignment & Total Express Consignment & $\begin{array}{l}\text { Percentage using } \\
\text { Simplified System }\end{array}$ \\
\hline 2011 & $10,465,378$ & $11,759,896$ & $88.9 \%$ \\
2012 & $11,916,785$ & $13,287,500$ & $89.7 \%$ \\
2013 & $13,844,620$ & $15,330,702$ & $90.3 \%$ \\
2014 & $15,823,479$ & $17,414,605$ & $90.8 \%$ \\
2015 & $18,827,520$ & $20,511,960$ & $91.7 \%$ \\
\hline
\end{tabular}

Source: Trade Statistics Data, Ministry of Finance, Taiwan. [Trade Statistics Data] 
Table 3 The express cargo handled by operators at Taoyuan Airport in 2014 (Measured by kg)

\begin{tabular}{llll}
\hline Operators $\backslash$ & Import Express Cargo & Export Express Cargo & Sub-Total \\
\hline TACT & $20,097,622$ & $12,886,548$ & $32,984,170$ \\
Ever Terminal & $13,309,517$ & 897,605 & $14,207,122$ \\
Far Glory (include DHL) & $44,569,975$ & $26,191,376$ & $70,761,351$ \\
EGAC & $14,539,221$ & $4,506,374$ & $19,045,595$ \\
FedEx & $14,055,217$ & $29,848,138$ & $43,903,355$ \\
UPS & $5,403,980$ & $18,555,710$ & $23,959,690$ \\
Total & $111,975,532$ & $92,885,751$ & $204,861,283$ \\
\hline
\end{tabular}

Source: Taoyuan Airport, compiled by author

In the SECCS, more than $97 \%$ of the cargoes are classified into Class One (C1), which are inspected by X-ray scan only and could be delivered to the consignee immediately after clearance. The expert system selects roughly 2 to $3 \%$ of the cargoes to be classified into Class Two (C2) or Class Three (C3). For C2 cargoes, the customs broker should bring the documents to be examined by the customs officer; for $\mathrm{C} 3$ cargoes, both the document and the cargo itself are inspected by the customs officer.

Among the 251 tax evasion cases, there are four major causes of how these cases were captured, as shown in Table 7. Surprisingly, only approximately $39 \%$ of tax evasion cases were captured by the SECCS, and were mostly fined for declaring a lower CIF value or a wrong tax code. Approximately $29 \%$ of the cases were captured by $\mathrm{X}$-ray scan. The duty officer may occasionally change the status of suspicious cargoes originally classified as $\mathrm{C} 1$ to $\mathrm{C} 3$ for inspection, and such cargoes contribute $19 \%$ of the 251 tax evasion cases; meanwhile, randomly selected cargoes for inspection contribute $13 \%$ of the cases collected.

When tax evasion cargoes are captured, the duty officer will then judge and decide on their cases with the corresponding penalty, as shown in Table 8. In approximately $50 \%$ of the cases, the shippers or customs brokers are deemed to have declared a lower CIF value to avoid taxes and duties. In $35 \%$ of the cases collected, shippers or customs brokers attempted to falsely declare or fudge the product's tax code to reduce or avoid the corresponding taxes.

An examination of the summary of tax evasion cases yielded several interesting findings and facilitated the identification of major factors influencing the SECCS' effectiveness. For example, 4 out of 36 customs officers were determined to be "difficult" ones, and they captured roughly $50 \%$ of the tax evasion cases; meanwhile, 15 out of 36

Table 4 Definitions of three channels of Customs inspection

\begin{tabular}{llll}
\hline $\begin{array}{l}\text { Inspection } \\
\text { Channel }\end{array}$ & Cargo Type & Inspection Procedures Needed & $\begin{array}{l}\text { Percentage of } \\
\text { total inspections }\end{array}$ \\
\hline Channel One (C1) & Tax-free cargo & $\begin{array}{l}\text { No inspection of both } \\
\text { document and cargo }\end{array}$ & $>97 \%$ \\
Channel Two (C2) & Random selected cargoes & Inspection of document only & $<2 \%$ \\
Channel Three (C3) & All tax-imposed cargoes & $\begin{array}{l}\text { Inspection of both } \\
\text { document and cargo }\end{array}$ & $<2 \%$ \\
\hline
\end{tabular}

Source: Customs Administration, Ministry of Finance, Taiwan 
Table 5 Four categories of express cargoes (based on CIF value)

\begin{tabular}{llll}
\hline Types of cargo $\backslash$ & Minimum CIF value & Tax & Inspection \\
\hline Express document & No & No & No \\
Low value express cargo & $<$ US\$100 & No & No \\
Taxed low value express cargo & US\$100- US\$1666 & Yes & Yes \\
Taxed high value express cargo & $>$ US\$1666 & Yes & Yes \\
\hline
\end{tabular}

Source: Customs Administration, Ministry of Finance, Taiwan

customs officers were deemed to be "easy" ones, and their total contribution to the capturing of tax evasion cases was less than $5 \%$.

Meanwhile, several difficult customs brokers were also observed; specifically three difficult customs brokers contributed to approximately $70 \%$ of the cases. Moreover, "hot" cargo categories were identified; for example, textile products accounted for $34 \%$ (tax rate of $12 \%$ ) of tax evasion cases, $30 \%$ for electronic products (tax rate of $7.5 \%$ ), and $8 \%$ for mechanical products (tax rate of $6 \%$ ). Flights that departed from Hong Kong contributed to more than $75 \%$ of tax evasion cases. With regard to the "Original Manufacturing Country", products made in Hong Kong accounted for 57 \% of tax evasion cases, whereas products made in China accounted for $37 \%$ of tax evasion cases, as shown in Table 9.

\section{In-depth analysis}

In the general analysis, an expected finding was that the flights departed from both Hong Kong and China carried the majority of tax evasion cargoes. Another expected finding was that the consignee and customs brokers attempted to apply for the items of a lower tax rate to avoid taxes and duties. However, such findings raise an important question: Why do significant differences exist between "difficult" and "easy" customs officers?

The logistic regression model was selected to obtain an in-depth and comprehensive understanding of the factors that influence the SECCS' effectiveness. Based on the data collected, three major criteria emerged together with fourteen variables available for analysis. The three major criteria are details of the inspector, details

Table 6 Criteria used by expert system

\begin{tabular}{llll}
\hline Criteria no.. & Item Name & Criteria no. & Item Name \\
\hline 1 & Manifest Classification & 10 & Ranking of Express Operator \\
2 & Customs Broker & 11 & Flight No. \\
3 & Shipper & 12 & Main Code of Bill of Lading \\
4 & Clearance Terminal & 13 & Sub-Code of Bill of Lading \\
5 & Tax Code & 14 & Consignee \\
6 & Storage Terminal & 15 & Cargo Name \\
7 & Manufacture Country & 16 & ClF Value \\
8 & Express Operator & 17 & Weight \\
9 & Port of Loading & &
\end{tabular}


Table 7 Causes of the tax evasion cargoes captured

\begin{tabular}{lll}
\hline Causes of the Tax Evasion Cases Captured & No. of cases & Percentage \\
\hline Captured by SECCS & 96 & $39 \%$ \\
Captured by X-Ray Scan & 74 & $29 \%$ \\
C1 changed to C3 & 48 & $19 \%$ \\
Random selection & 33 & $13 \%$ \\
Total & 251 & $100 \%$
\end{tabular}

Source: Taipei Branch, Customs Administration, compiled by author

of the customs broker, and the cargo information collected from the manifest (see Table 10). Details on the inspector include the inspector's age, working years, gender, working experience in express operations, ranking and position in the CA, and educational background. Details on the customs broker include capital, number of employees, years of establishment, and working years for express operations. Cargo information includes the departure port, cargo's CIF value, and the weight and quantity of the cargoes declared in the manifest. Based on the 251 tax evasion cases together with the related detailed information, we attempted to identify and measure the influence of each variable. The analysis results are presented in Appendix A.

Based on the findings, we identified the following variables that significantly influence tax evasion cases:

1. Inspector: Significant differences exist among inspectors. After analyzing the differences in the backgrounds of inspectors, we determined certain characteristics that distinguish the "difficult" ones from other types of inspectors. These characteristics are as follows: male, younger in age, junior in the CA service history, senior in the express operations (experienced in identifying tax rate and CIF value), lower ranking in the express business but has more experience in the field, and higher educational attainment.

2. Customs broker: The characteristics of a "clean" customs broker include higher capital, more employees, longer years of establishment, and longer history in the express businesses.

3. Cargo quantity, value, and weight: Results indicate that when the quantity, value, and weight of cargoes are higher, the capture rate increases.

Table 8 Cases of tax evasion

\begin{tabular}{lll}
\hline Cases of Tax Evasion & No. of cases & Percentage \\
\hline Declared Lower CIF & 126 & $50 \%$ \\
False or Fudge on Tax Code & 89 & $35 \%$ \\
False or Fudge on Cargo Name, Quantity or Manufacturer & 23 & $9 \%$ \\
Counterfeit or Fake Product & 4 & $2 \%$ \\
Others & 9 & $4 \%$ \\
Total & 251 & $100 \%$ \\
\hline
\end{tabular}

Source: Taipei Branch, Customs Administration, compiled by author 
Table 9 Summary of major tax evasion causes

\begin{tabular}{lllll}
\hline Causes\ Agent Code. & A & B & C & D \\
\hline Customs Officer & $16.8 \%$ & $12.2 \%$ & $10.7 \%$ & $10.0 \%$ \\
Customs Broker & $25.2 \%$ & $25.0 \%$ & $19.4 \%$ & $12.9 \%$ \\
Cargo Category & $34.3 \%$ (textile) & $30.0 \%$ (electronic) & $8.1 \%$ (mechanic) & $4.9 \%$ (Accessories) \\
Departure Port & $75.6 \%(\mathrm{HK})$ & $10.9 \%$ (China) & & \\
Original Manufactured Country & $57.4 \%(\mathrm{HK})$ & $36.9 \%$ (China) & $3.4 \%$ (Japan) & \\
\hline
\end{tabular}

Source: compiled by author

Furthermore, we have used the statistical software to analyse the significance or the impact of the three criteria with fourteen variables on the 251 tax-invasion cases collected (as shown in Appendix A and B).

Findings reveal that the inspector is the most significant factor that influences the system's effectiveness. To examine the vital role of the human factor in capturing tax evasion cargoes, we further explored the policy aspect for answers.

\section{System flaw}

To ascertain why the expert system does not work effectively as expected, we interviewed two high-ranking senior customs officers with over thirty years of experience in the CA, and two senior customs brokers with over fifteen years of experience in the air-cargo express business. We posed the question, "Why does the system fail to work?" to customs officers; meanwhile, we posed the question, "How do you utilize the SECCS to attract business?" to customs brokers. We subsequently compared their answers to identify the critical factors that hinder the proper operation of the expert system.

The customs officers mentioned that the definition of a "bag" is the major cause of system flaw. In 1996, to entice international express operators to choose Taoyuan

Table $\mathbf{1 0}$ Criteria and variables collected for analysis

\begin{tabular}{ll}
\hline Criteria & Variables \\
\hline Inspector & Age \\
& Working experience (years) \\
& Gender (male, female) \\
& Years of experience in express inspection \\
& Position in Customs Office \\
Customs Broker & Education background \\
& Capital \\
& No. of employee \\
& Established years of Customs Broker \\
Cargo Information & Number of years for express cargo business \\
& Airline Code \\
& ClF value \\
& Cargo weight \\
Cargo quantity
\end{tabular}


Airport as their Asian hub, the CA increased the maximum gross weight of the bag from $40 \mathrm{~kg}$ to $70 \mathrm{~kg}$ and raised the tax-free CIF value of the bag to NT\$50,000 as incentives. Senior customs officers acknowledged customs brokers that bundled small packages into one bag and then declared their total CIF value as less than NT\$50,000 as the major cause of tax evasion.

In practice, the average rate to deliver an express cargo per kilogram from the coastal cities of China to Taiwan is around NT\$ 100. In the case of a bag from China weighing $70 \mathrm{~kg}$, the total express cost will be around NT\$ 7,000 (NT\$100 multiplied by $70 \mathrm{~kg}$ ). Assuming that the express cost is $5 \%$ of cargo value, the bag's CIF value will be around NT $\$ 140,000$, which is nearly three times of the taxfree CIF value of one bag $(\mathrm{NT} \$ 50,000)$. This case explains why the majority of experienced inspectors could easily capture the bag involved in tax evasion.

Meanwhile, in practice, a bag could load as many packages from different consignees as possible provided that the total weight is below $70 \mathrm{~kg}$. For customs officers, this condition induces difficulty in checking the nature of packages, thereby facilitating tax evasion.

With regard to cargo categories, experienced officers could easily identify two high tax rate cargoes (i.e., textile and electronic cargoes) from the X-ray scan conveyer and impose the appropriate tax charges.

Interviews with customs brokers further confirmed the system flaw caused by a bag and the CIF value. More than 500 customs brokers provide service at Taoyuan Airport, and these custom brokers must compete with others in terms of efficiency, and mostly, in saving on taxes and duties. Thus, customs brokers must maximize the benefits obtainable from each bag. This case explains why the interviewed customs brokers responded that they must declare the CIF value of each bag that amounts to less than NT\$50,000 to save the duties and taxes of their clients and expect that their bags could pass through the system without going through inspection.

Meanwhile, difficult customs officers will significantly influence the business of the air-cargo terminal. For example, if difficult customs officers are stationed at "A" Terminal, the majority of the express cargoes will be immediately moved to other terminals to be inspected by easy officers. Both the Ministry of Finance and the Customs Authority often receive complaints from terminal operators regarding business losses caused by difficult officers, and from customs brokers and consignees concerning delayed cargoes. This aspect explains the present findings on the background of inspectors, and the reason why the majority of inspectors are easy.

\section{Trade-off}

The flaw in the express consignment clearance system is apparently an untold secret. In addition, the expert system could only function partly, and more than $97 \%$ of express cargoes were inspected only by X-ray scan, regardless of the accuracy of the cargo category, department port, or tax rate declared on the manifest.

In 2014, the government expressed its desire to copy the successful model of the SECCS to develop the shipping express business between Taiwan and China at Taipei Port, which is approximately $20 \mathrm{~km}$ away from Taoyuan Airport. The CA introduced a 
modified the SECCS and fixed some of the air express system's flaws. For example, the packages of different consignees could not be bundled into one bag, and the big shipment of one consignee could not be separated into several smaller shipments to avoid tax declarations. In other words, a large part of the argument over bags has been removed, and the evasion of taxes is allowed minimal opportunity.

Compared with the air express system, the shipping express system has fixed most major flaws in the simplified consignment clearance system, and few advantages could be enjoyed by forwarders, shippers, and consignees. Expectedly, the majority of operators do not utilize the shipping express service, and few express businesses from China move from Taoyuan Airport to Taipei Port.

Achieving the balance between the effectiveness and efficiency of the express consignment clearance system is challenging. Thus, the development of the shipping express at Taipei Port could be used as an example when the system moves forward to achieve effectiveness and determine the system's influence on the business.

\section{Conclusions and recommendations}

The present research examined the express consignment clearance system at Taoyuan Airport and identified the critical factors that induce tax evasion. This study used general and logistic regression analyses in the evaluation. the SECCS captured approximately $39 \%$ of the tax evasion cases, and the inspectors captured the other $61 \%$. Meanwhile, the two major causes of tax evasion were determined to be the lower CIF value and the false tax code, which accounted for roughly $85 \%$ of total cases. However, the human factor was considered the most significant aspect that influences the system. This finding prompted us to review the development of the SECCS in Taiwan and to identify the major system flaws. We interviewed senior customs officers and customs brokers; based on these interviews, we found that the loose definition of a "bag" allowed the broker to bundle packages of different consignees into one bag, or separate a large shipment of one consignee into several bags to avoid customs inspection for tax evasion.

From the viewpoint of the CA, maintaining the balance between the efficiency and effectiveness of the customs inspection system is a constant challenge. At Taoyuan Airport, the grey area in the SECCS seems to be the incentives that attract express businesses. In 2014, more than $91 \%$ of express cargoes used the SECCS. For example, if the SECCS moves forward to achieve effectiveness in capturing more tax evasion cargoes, and the proportion of C3 increases from $2-3 \%$ to $10 \%$, the economic impact and complaints from consignees and brokers must be excessive to be afforded by the CA. However, Taipei Port is developing a shipping express business with a modified system that leaves little space for tax evasion. This situation could be another case study for the trade-off between the effectiveness and efficiency of customs inspection, and the CA should seriously consider whether or not the SECCS should be a long-term strategy to keep the two different inspection standards of the SECCS in North Taiwan.

The findings of this study provide other topics for future research on express consignment clearance service, including the economic impacts on the different government policies of the CA and the trade-off between the effectiveness and efficiency of the express cargo inspection system. 


\section{Appendix 1}

Table 11 Binary logistic analysis of the significance of the individual factor

\begin{tabular}{|c|c|c|c|c|c|c|}
\hline Criteria & Variable & $\begin{array}{l}\text { Description of } \\
\text { each variable }\end{array}$ & $\operatorname{Estimate}(\beta)$ & Std. Error & Signif. Codes & $\operatorname{Exp}(\beta)$ \\
\hline & \multirow{12}{*}{$\begin{array}{l}\text { Inspector code (the records } \\
\text { of } 12 \text { customs inspectors } \\
\text { were collected, and they } \\
\text { were named as A, B..L) }\end{array}$} & A & 1.850 & 0.752 & * & 6.362 \\
\hline & & B & 1.806 & 0.728 & * & 6.092 \\
\hline & & $C$ & 2.280 & 0.720 & $* *$ & 9.781 \\
\hline & & $D$ & 2.146 & 0.763 & $* *$ & 8.554 \\
\hline & & $E$ & 1.720 & 0.794 & * & 5.589 \\
\hline & & $\mathrm{F}$ & 3.931 & 0.902 & $* * *$ & 51 \\
\hline & & G & 2.413 & 0.768 & $* *$ & 11.178 \\
\hline & & $\mathrm{H}$ & 2.852 & 0.742 & $* * *$ & 17.328 \\
\hline & & I & 2.150 & 0.795 & $* *$ & 8.589 \\
\hline & & J & 2.527 & 0.732 & $* * *$ & 12.522 \\
\hline & & K & 2.516 & 0.733 & $* * *$ & 12.388 \\
\hline & & L & 2.537 & 0.740 & $* * *$ & 12.646 \\
\hline & \multirow{12}{*}{$\begin{array}{l}\text { Airline (the code of } \\
\text { the flight plane) }\end{array}$} & B7 & -4.231 & 0.423 & $* * *$ & 0.014 \\
\hline & & $\mathrm{BR}$ & -2.866 & 0.214 & $* * *$ & 0.056 \\
\hline & & $\mathrm{Cl}$ & -2.650 & 0.222 & $* * *$ & 0.070 \\
\hline & & CK & -3.291 & 0.488 & $* * *$ & 0.037 \\
\hline & & $C X$ & -2.579 & 0.268 & $* * *$ & 0.075 \\
\hline & & ER & -1.822 & 0.754 & * & 0.161 \\
\hline & & FM & -4.712 & 1.019 & $* * *$ & 0.008 \\
\hline & & $\mathrm{GE}$ & -3.239 & 0.402 & $* * *$ & 0.039 \\
\hline & & KA & -2.837 & 0.268 & $* * *$ & 0.058 \\
\hline & & LD & -2.658 & 0.491 & $* * *$ & 0.070 \\
\hline & & MF & -2.585 & 0.455 & $* * *$ & 0.075 \\
\hline & & NX & -3.092 & 0.246 & $* * *$ & 0.045 \\
\hline & \multirow[t]{3}{*}{ Cargo Info. } & CIF (value) & 0.0008 & 0.0001 & $* * *$ & 1.0008 \\
\hline & & Weight & 0.019 & 0.001 & $* * *$ & 1.019 \\
\hline & & Quantity & 0.001 & 0.0001 & $* * *$ & 1.001 \\
\hline \multirow[t]{8}{*}{ Inspector } & Age of Inspector & & -0.021 & 0.005 & $* * *$ & 0.972 \\
\hline & $\begin{array}{l}\text { Working Years } \\
\text { of Inspector }\end{array}$ & & -0.029 & 0.005 & $* * *$ & 0.973 \\
\hline & Gender of Inspector & Male & 0.771 & 0.284 & $* *$ & 2.163 \\
\hline & $\begin{array}{l}\text { Experience of } \\
\text { express business }\end{array}$ & & 0.622 & 0.082 & $* * *$ & 1.863 \\
\hline & \multirow[t]{2}{*}{ Position of Inspector } & Clerk & 1.439 & 0.712 & * & 4.217 \\
\hline & & Senior Clerk & 1.844 & 0.712 & $* *$ & 6.323 \\
\hline & \multirow{2}{*}{$\begin{array}{l}\text { Education Background } \\
\text { of Inspector }\end{array}$} & university & -0.342 & 0.173 & * & 0.709 \\
\hline & & college & -0.427 & 0.170 & $*$ & 0.652 \\
\hline
\end{tabular}


Table 11 Binary logistic analysis of the significance of the individual factor (Continued)

\begin{tabular}{|c|c|c|c|c|c|c|}
\hline \multirow{6}{*}{$\begin{array}{l}\text { Customs } \\
\text { Broker }\end{array}$} & \multirow[t]{2}{*}{ Companies } & A & -1.04 & 0.201 & $* * *$ & 0.351 \\
\hline & & B & -1.20 & 0.210 & *** & 0.299 \\
\hline & $\begin{array}{l}\text { Capital of } \\
\text { customs broker }\end{array}$ & & -0.694 & 0.177 & $* * *$ & 0.499 \\
\hline & No. of employees & & -0.108 & 0.019 & $* * *$ & 0.896 \\
\hline & Years Established & & 0.057 & 0.022 & $* *$ & 1.059 \\
\hline & Years of Express Business & & 0.074 & 0.028 & *** & 1.077 \\
\hline
\end{tabular}

Remark: Signif. Codes: 「***」:0,「**」:0.001,「*」:0.01,「.」:0.1

\section{Appendix 2}

Table 12 Summary of the Regression Model

\begin{tabular}{llccc}
\hline Model & $R$ & R Square & Adjusted R Square & Std. Error of the Estimate \\
\hline Total Group & 0.896 & 0.803 & 0.796 & 23.672
\end{tabular}

Predictors: (Constant), age of Inspector, working years of inspector, experience of express business, companies, capital of customs broker, no. of employees, years of express business, CIF (value), weight, Quantity

Received: 10 May 2016 Accepted: 19 October 2016

Published online: 03 November 2016

\section{References}

Album FA (2010) Regional cooperation on trade and transport facilitation. impact of trade facilitation on export competitiveness: a regional perspective., pp 66-71

Cantens T, Raballand G, Bilangna S (2010) Reforming customs by measuring performance: a cameroon case study'. World Customs J 4(2):55-74

Chapman J (2004) System failure: why governments must learn to think differently., Demos

Duval Y, Battacharya D, Hossain SS, Wenjing C, Wei L, Chaturvedi S, Adhikari SR (2006) An exploration of the need for and cost of selected trade facilitation measures in Asia-Pacific in the context of the WTO negotiations. Studies in Trade and Investment 57

Geourjon A-M, Laporte B (2005) Risk management for targeting customs controls in developing countries: a risky venture for revenue performance?'. Public Adm Dev 25(2):105-113

Heaver TD (1992) The role of customs administration in the structure and efficiency of international logistics: An international comparison. Int J Logist Manag 3(1):63-72

Puengpradit W 2010 Trade Facilitation and Customs Regulatory Control: A Study of Express Consignment Operations in Thailand. PHD Thesis. University of Canberra, Canberra

Salama R, Şenbursa N (2014) Cost efficiency measures in maritime electronic communications. J Marit Res 10(3):51-60

Trade Statistics Data Bank, Customs Administration, Ministry of Finance, Taiwan

World Customs Organization (WCO) (1999) International Convention on the Harmonization and Simplification of Customs Procedures (as amended) (Revised Kyoto Convention). WCO, Brussels

Yeh RFC (2008) Today's immigration legal system: flaw and possible reforms. Rutgers Race L Rev 10:441

Zhang A (2002) Electronic technology and simplification of customs regulations and procedures in air cargo trade. J Air Transp 7(2):87-102

\section{Submit your manuscript to a SpringerOpen ${ }^{\circ}$ journal and benefit from:}

- Convenient online submission

Rigorous peer review

- Immediate publication on acceptance

- Open access: articles freely available online

- High visibility within the field

- Retaining the copyright to your article

Submit your next manuscript at $\gg$ springeropen.com 